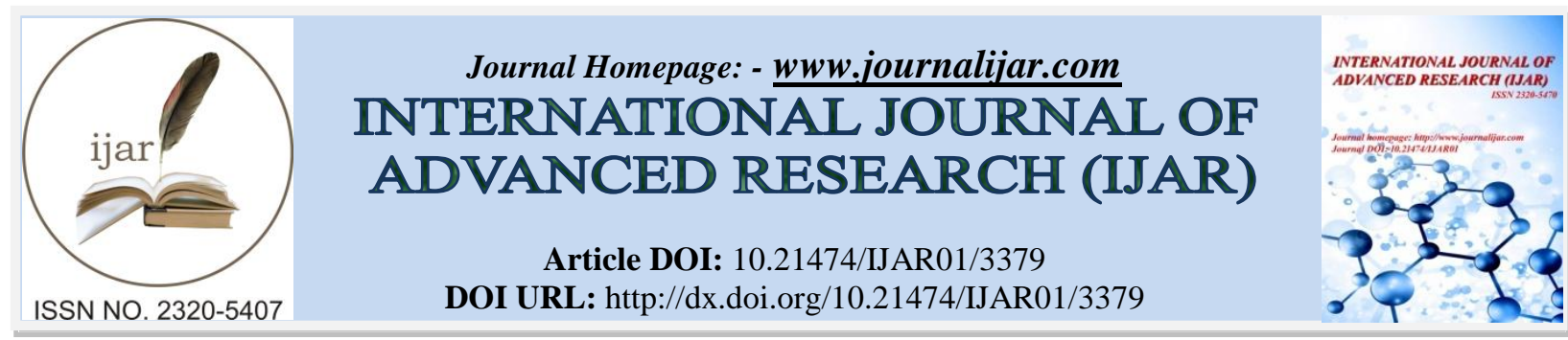

RESEARCH ARTICLE

\title{
ASSESSMENT OF PLATELET COUNT AND PLATELET INDICES IN PREGNANCY INDUCED HYPERTENSION.
}

Sujata $\mathbf{N}^{1}$, Shinde $P \mathbf{J}^{2}$, Verma $A^{1}$, Ghatge R. $M^{1}$, Gupta $S^{1}$ and Inamdar A. $A^{1}$.

1. Post Graduate student, Department of Pathology, D.Y. Patil Medical College, Kolhapur.

2. Associate Professor, Department of Pathology, D.Y. Patil Medical College, Kolhapur.

\section{Manuscript Info}

Manuscript History

Received: 18 December 2016

Final Accepted: 21 January 2017

Published: February 2017

Key words:-

PIH, Thrombocytopenia, MPV, PDW.

\begin{abstract}
Hypertensive disorders of pregnancy complicate up to $10 \%$ of pregnancies worldwide, constituting one of the greatest causes of maternal and perinatal morbidity and mortality. The basic pathology of pregnancy induced hypertension (PIH) is poor placentation, and vasospasm of vessels along with alteration of hematological profile. The study was conducted in Dr. D. Y. Patil Hospital and Research institute, Kolhapur, on 50 patients clinically diagnosed as $\mathrm{PIH}$, and 50 normotensive pregnant women both with gestational age $\geq 20$ weeks. In the present study of the $50 \mathrm{PIH}$ cases 22 cases (44\%) had severe PIH (diastolic BP $\geq 110 \mathrm{mmHg}$ ) and 28 cases $(56 \%)$ had mild PIH (diastolic BP $\leq 100 \mathrm{mmHg}$ ) PIH was found to be common in young primigravidas. Thrombocytopenia was the most common haematological aberration seen in PIH. In the present study thrombocytopenia $(<1.5$ lakhs $)$ was seen in $12(24 \%)$ of total PIH cases. We made a conclusion that simple and routine tests like CBC with platelet count and platelet indices are highly helpful in suspecting deranged coagulation early in courses of disease and have a crucial role in reducing mortality and morbidity of both mother and fetus.
\end{abstract}

Copy Right, IJAR, 2017,. All rights reserved.

\section{Introduction:-}

Hypertensive disorders of pregnancy, including preeclampsia complicate upto $10 \%$ of pregnancies worldwide, constituting one of the greatest causes of maternal and perinatal morbidity and mortality worldwide. The term hypertensive disorders of pregnancy includes a heterogeneous collection of disease complicating pregnancy and form one of the deadly triad along with haemorrhage and infection.

The diagnosis of pregnancy induced hypertension is made in women whose blood pressure reaches 140/90mmHG or greater for first time at $\geq 20$ weeks of gestation. Preeclampsia is characterized by hypertension (Blood pressure of $140 / 90 \mathrm{mmHg}$ or greater), proteinuria $(>0.3 \mathrm{~g} / \mathrm{dl})$, edema and new signs of end organ dysfunction and begins as early as $20^{\text {th }}$ gestational week. Eclampsia is occurance of seizures in women with preeclmpsia which develops before, during or after labour. ${ }^{1}$

The basic pathology of preeclampsia is endothelial dysfunction, poor placentation, and vasospasm of vessels along with alteration of hematological profile ${ }^{2}$. Out of all hematological abnormalities that occur in PIH, thrombocytopenia is the most common seen in $11-29 \%$ of patients. These pregnancies also are associated with 
qualitative changes suggesting increased platelet production and destruction. There is shortened life span, increased number of megakaryocytes in bone marrow and an increase number of immature platelets seen in peripheral smear ${ }^{4}$. Walker J.J. et al showed that in pregnancy induced hypertension there are changes in platelet number, platelet survival and mean platelet volume, which have been interpreted as evidence of increased platelet consumption ${ }^{9}$. The MPV and PDW were elevated proportionally with the severity of pre-eclampsia when compared with the normotensive control group. There is a gradual increase in MPV from normotensive pregnant women to preeclampsia and eclampsia. This increase in MPV in pre-eclampsia and eclampsia probably indicate hyperdestruction of platelets due to shorter platelet half-life ${ }^{11}$. There was an increase in PDW from normotensive pregnant women to pre-eclampsia and eclampsia in the study conducted by Tygart et al. This probability reflects increased platelet turnover which would support the idea that platelet survival time is decreased resulting in increased destruction of platelets ${ }^{12}$. Clinically, platelet indices can be a useful screening test for early identification of pre-eclampsia and eclampsia. Also platelet indices can assess the prognosis of PIH in pregnant women.

\section{Methodology:-}

After ethical approval one year prospective study was carried out in D Y Patil Hospital and Research Institute during the period of June 2015 to May 2016. This study was undertaken in Department of Pathology with collaboration of department of Obstetrics and Gynecology, Dr D Y Patil Hospital and Research Institute Kolhapur. The present study includes 50 patients aged 18-35 years clinically diagnosed as pregnancy induced hypertension with gestational age $\geq \mathbf{2 0}$ weeks attending outpatient department or admitted in antenatal ward/labour room in department of OBG, Dr. D. Y. Patil Hospital and Research institute, Kolhapur. Fifty normotensive pregnant women in the age group of 18-35 years with gestational age $\geq \mathbf{2 0}$ weeks were included in the control group. CBC valves were determined by Mindray BC- 3000 Plus hematology analyser which is a fully automated three part hematology analyser. Platelet count, mean platelet volume(MPV), platelet distribution width(PDW) estimation was compared between the normotensive pregnant women with PIH patients. The statistical analysis used was mean, standard deviation and students $\mathrm{t}$-test. The $\mathrm{p}$ value $<0.05$ was accepted as significant.

\section{Results:-}

PIH is common in young primigravidas, in the present study mean age was $23.8 \pm 3.56$ years and primigravidas constituted the majority of patients $(68 \%)$. Thrombocytopenia is the most common haematological aberration seen in PIH. In the present study thrombocytopenia ( $<1.5$ lakhs) was seen in $12(24 \%)$ of total PIH cases. The mean platelet count in mild PIH was 2.23 \pm 0.641 acs/cumm and that in severe PIH was $1.67 \pm 0.55$ lacs/cumm. The mean platelet count in normotensive control was $3.14 \pm 0.80 \mathrm{lacs} /$ cumm. (Table No. 1)

Table 1:- Table showing mean platelets count in mild and severe PIH and control cases

\begin{tabular}{|c|c|}
\hline & $\begin{array}{c}\text { Mean platelet count } \pm \text { SD } \\
\text { (lacs/cumm) }\end{array}$ \\
\hline Control(n=50) & $3.14 \pm 0.80$ \\
\hline Mild PIH(n=28) & $2.23 \pm 0.64$ \\
\hline Severe PIH(n=22) & $1.67 \pm 0.55$ \\
\hline
\end{tabular}

\section{Mean Platelet Volume and Platelet distribution width (PDW);-}

In the present study MPV ranged from 7.6 femtolitre to $12.6 \mathrm{fl}$ in mild PIH \& $7.8 \mathrm{fl}$ to $13.6 \mathrm{fl}$ in severe PIH. Mean MPV in PIH was significantly higher $(10.57 \pm 2.67 \mathrm{fl})$ compared to that in control group $(7.74 \pm 0.92 \mathrm{fl}) \mathrm{p}<0.05$ significant. In the present study mean PDW in PIH cases was $13.2 \pm 1.97 \%$ whereas it was $11.82 \pm 1.52 \%$ in control. Mean PDW was significantly increased $(\mathrm{p}<0.05)$ in PIH group compared to control (Table No. 2)

Table 2:- Table showing mean MPV in PIH and control cases

\begin{tabular}{|l|l|l|}
\hline & Mean MPV \pm SD (fl) & Mean PDW \pm SD (\%) \\
\hline PIH $(\mathrm{n}=50)$ & $10.57 \pm 2.67$ & $13.2 \pm 1.97$ \\
\hline Control $(\mathrm{n}=50)$ & $7.74 \pm 0.92$ & $11.82 \pm 1.52$ \\
\hline
\end{tabular}

\section{Discussion:-}

Women with severe pre-eclampsia develop a variety of hematological aberrations. These hematological aberrations have an impact on the outcome of delivery of these patients so that aggressive therapy can be initiated to prevent maternal and neonatal morbidity and mortality. 
Thrombocytopenia is the most common haematological aberration seen in PIH. . It is caused by increased platelet destruction as shown by decreased platelet lifespan, increased number of megakaryocytes in the bone marrow and an increased proportion of young, oversize platelets (megathrombocytes) in the peripheral blood film. Thrombocytopenia is associated with progressive disease \& also with disease severity. Thrombocytopenia occurs in $15 \%$ of patients with pre-eclampsia. A significant reduction in platelet count is seen frequently during and even before the onset of disease $e^{13}$.

Kelton J. G, et $\mathrm{al}^{4}$ in their study observed that $34 \%$ of patients had thrombocytopenia, Thomas A, et al in their study reported that $16 \%$ had thrombocytopenia ${ }^{14}$. Vrunda J K. reported $41 \%$ thrombocytopenia, Ruchi Verma et al reported $31 \%$ thrombocytopenia in their studies. In the present study $24 \%$ had thrombocytopenia (Table no. 3 ).

Table 3:- Table showing comparison of percentage of PIH patients having thrombocytopenia in different studies.

\begin{tabular}{|c|c|}
\hline Authors & Thrombocytopenia(\%) \\
\hline Kelton J. G, et al ${ }^{4}(\mathrm{n}=26)(1985)$ & $34 \%$ \\
\hline Thomas A. et al $^{14}(\mathrm{n}=80)(1998)$ & $16 \%$ \\
\hline Vrunda JK $^{15}(\mathrm{n}=72)(2004)$ & $41 \%$ \\
\hline Ruchi Verma et al ${ }^{16}(\mathrm{n}=35)(2015)$ & $31 . \%$ \\
\hline Present study $(\mathrm{n}=50)(2016)$ & $24 \%$ \\
\hline
\end{tabular}

Severity of PIH and thrombocytopenia are closely correlated which indicates that thrombocytopenia is directly proportional to severity of PIH. The mean platelet count in present study were: 3.14 lacs/cumm in normotensive pregnant women and 2.23 lacs/cumm in mild PIH and 1.67 lacs/cumm in severe PIH cases. When mean platelet count was compared between control and PIH cases, a significant decrease in platelet number was observed and correlated well with the valves of other studies. ( Table No-4)

Table 4:- Table showing comparison of mean platelet count in normotensive and varying degree of PIH and correlation with other studies

\begin{tabular}{|c|c|c|c|}
\hline & \multicolumn{3}{|c|}{ Mean Platelet volume (lacs/cumm) } \\
\hline Authors & Control & Mild PIH & Severe PIH \\
\hline Kulkarni and Sutharia $^{20}(\mathrm{n}=90)(1983)$ & 2.5 & 1.84 & 1.19 \\
\hline Srivastava M $^{17}(\mathrm{n}=119)(1995)$ & 1.94 & 1.79 & 1.64 \\
\hline Vrunda Jk $^{15}(\mathrm{n}=122)(2004)$ & 2.2 & 2.01 & 1.4 \\
\hline Jambhulkar et al $^{18}(\mathrm{n}=194)(2001)$ & 2.38 & 2.30 & 1.70 \\
\hline S Mohapatra $^{19}(\mathrm{n}=90)(2007)$ & 2.38 & 2.23 & 1.82 \\
\hline Ellora Devi et al $^{21}(\mathrm{n}=60)(2012)$ & 2.44 & 1.82 & 1.42 \\
\hline Present study $(\mathrm{n}=100)(2016)$ & 3.14 & 2.23 & 1.67 \\
\hline
\end{tabular}

The normal range for MPV is $8.63 \pm 0.87 \mathrm{fl}$ in many studies and distribution of platelet sizes is related to PDW. Platelet size and platelet distribution width are both increased in pre-eclamptic patients even with normal platelet counts. Rise in MPV \& PDW can predict the haemostatic abnormality in them ${ }^{7}$.

Walker J. J. et $\mathrm{al}^{9}$ has indicated that rising MPV can be used as a marker for intervention in pre-eclamptic patients. Stubbs et al has reported increased MPV of $11.5 \mathrm{fl}$ in his study of PIH patients compared to control subjects (9.7fl). Similar observation was made by various other authors and also in present study. (Table no. 5).

Table 5:- Table showing comparison of mean MPV in present study with other studies.

\begin{tabular}{|c|c|c|}
\hline & \multicolumn{2}{|c|}{ Mean Platelet Volume(fl) } \\
\hline Authors $^{7}$ & Control & PIH \\
\hline Stubbs et al $^{7}(\mathrm{n}=20)(1986)$ & 11.5 & 9.7 \\
\hline Giles et al $^{10}(\mathrm{n}=550)(1987)$ & 8.7 & 9.9 \\
\hline Ahmed et al $^{22}(1993)$ & 9.6 & 10.2 \\
\hline Vamseedhar et al $^{11}(\mathrm{n}=182)(2011)$ & 8.2 & 10.2 \\
\hline Fahmi E M et al $^{23}(\mathrm{n}=70)(2013)$ & 9.5 & 10.6 \\
\hline Present study(n=100) $(2016)$ & 7.7 & 10.7 \\
\hline
\end{tabular}


Increased mean platelet distribution width of $13.2 \%$ in PIH case compared to $11.82 \%$ in control cases was observed in present study. Similar observation was made by various other authors (Table No:6)

Table 6:- Table showing comparison of mean platelet distribution width (PDW) in present study with other studies

\begin{tabular}{|c|c|c|}
\hline & \multicolumn{2}{|c|}{ Mean PDW (\%) } \\
\hline Authors & Control & $\mathrm{PIH}$ \\
\hline${\text { Giles et } \mathrm{al}^{10}(1987)(\mathrm{n}=550)}$ & 12 & 16 \\
\hline Vamseedhar et al $^{1 \mathrm{I}}(2011)(\mathrm{n}=182)$ & 11.07 & 15.51 \\
\hline Fahmi E M et al $^{23}(2013)(\mathrm{n}=70)$ & 11.2 & 13.99 \\
\hline Present study $(n=100) 2016$ & 11.82 & 13.2 \\
\hline
\end{tabular}

\section{Conclusion:-}

Pregnancy induced hypertension is the most common complication of pregnancy and remains a leading cause of maternal and fetal morbidity \& mortality. As a result of the haemostatic aberrations in PIH, postpartum hemorrhages sometimes so severe as to lead to maternal death may occur. Fetal growth retardation is more frequent in the thrombocytopenic groups. This study gives an outline of the investigations to be done in cases of PIH which can alert the physician of the severity of disease so that appropriate and timely management can be initiated. The estimation of platelet count and platelet indices is a reliable method. In this study an attempt has been made to assess the role of platelet count and platelet indices like MPV and PDW in PIH patients.

\section{References:-}

1. Cunningham F. G, et al "Hypertensive disorders in pregnancy." Chapter 24 in William's Obstetrics, $21^{\text {st }}$ Edn, New York, McGraw Hill, 2001: pp 567.

2. Turner D. R, Reid H, \& Fox H- "Pathology of kidney, nervous system \& cardiovascular system in pregnancy by Fox Harold in Haines \& Taylor Obstetrical \& Gynecological pathology, $5^{\text {th }}$ Edn, Spain, Churchill Livingstone, 2003: PP 1505-1551.

3. Burrows R. F, et al. "A prospective study investigation the mechanism of thrombocytopenia in preeclampsia". Obstet Gynecol 1987; 70(3); 334-38.

4. Kelton J. G, Hunter D. J, and Neame P. B, "A platelet function defect in preeclampsia". Obstet Gynecol 1985; 65(1):107-9.

5. Schwartz M. L, and Brenner W. E, "Pregnancy-induced hypertension presenting with life-threatening thrombocytopenia". Am J obstet Gynecol 1983;146(7): 756-9.

6. McCrae K. R, Samuel. P. and Schreiber A. D, "Pregnancy associated thrombocytopenia: Pathogenesis and Management." Blood 1992; 80(11): 2697-2714.

7. Stubbs T. M, et al. "Evidence of accelerated platelet production and consumption in nonthrombocytopenic preeclampsia." Am J obstet Gynecol 1986; 155(2): 263-5.

8. O'Brien W. F, et al., "Alteration in platelet concentration and aggregating in normal pregnancy and preeclampsia." Am J obstet Gynecol 1986; 155(3): 486-90.

9. Walker J. J, et al. "Can platelet volume predict progressive hypertensive disease in pregnancy?" Am J obstet Gynecol 1989; 161(3): 676-9.

10. Giles $\mathrm{C}$ and Inglis T. C, "Thrombocytopenia and macrothrombocytosis in gestational hypertension." Br J Ostet Gynecol 1981; 88: 1115-9.

11. Vamseedhar Annam, Srinivasa K, Santhosh K Yatnatti, Suresh D. R. Evaluation of platelet indices and platelet counts and their significance in preeclampsia and eclampsia. Int J Bio Med Re. 2011; 2 (1):425-28.

12. Tygart SG,et al "Longitudinal study of platelet indices during normal pregnancy." Am J Obstet Gynaecol. 1986;154: 883-887.

13. Leduc L, Wheeler JM, Kirshon B, Mitchell P, Cotton DB. Coagulation profile in severe preeclampsia. Obstet \& Gynecol, 1992; 79(1):14-18.

14. Thomas A et al, Coagulation profile in pregnancy induced hypetension." Indian Journal of Hematology and Blood Transfusion, 1998; 16(1):7-11.

15. Vrunda JK, Saila S. Lowered Platelet Count: A prognostic index in pregnancy induced hypertension. J Obstet Gynaecol Ind. 2004; 54(3):235-236.

16. Ruchi Verma et al. Study on platelet indices in pregnancy induced hypertension. J EBMH Nov 2015; 2(44) 8035-39

17. Srivatsava M. Pregnancy induced hypertension and antithrombin-III Indian J Pathol Microbiol 1995;38(3):41. 
18. Jambhulkar S, Shrikhande A, Shrivastava R, Deshmukh K. Coagulation profile in pregnancy induced hypertension. Indian Journal of Hematology and Blood Transfusion 2001; 19 (1): 3-5.

19. S. Mohapatra, B. B. Pradhan, U. K. Satpathy, Arati Mohanty J. R. Pattnaik. Platelet Estimation: Its prognostic value in Pregnancy induced hypertension. Indian J Physiol Pharmacol 2007; 51(2): 160-164 .

20. Kulkarni RD, Sutaria UD. Platelet counts in toxaemias of pregnancy. Journal of Obstetrics and Gynaecology of India 1983; 33:321-325.

21. Ellora Devi. Combination of platelet and uric acid estimation can predict severity of PIH better. Int J Pharm Bio Sci 2012;3(3):1039- 45.

22. Ahmed $\mathrm{Y}$ et al, Retrospective analysis of platelet numbers and volumes in normal pregnancy and in preeclampsia. BJOG 1993; 100(3):216-220.

23. Fahmi E M et al, Variations of Platelets Indices in Pregnancy Induced Hypertension J Physiobiochem Metab 2013, 2(1):1-3. 